\title{
The Effects of Pulmonary Arterial Hypertension on the Heart Work Dynamics: Gender Differences
}

\author{
Ivan Kocic* and Katarzyna Sztormowska Achranowicz \\ Department of Pharmacology, Medical University of Gdansk, Poland \\ *Corresponding author: Ivan Kocic, Department of Pharmacology, Medical University of Gdansk, Poland
}

\section{ARTICLE INFO}

Received: 萬 July 08, 2019

Published: 蔧 July 15, 2019

Citation: Ivan Kocic, Katarzyna Sztormowska Achranowicz. The Effects of Pulmonary Arterial Hypertension on the Heart Work Dynamics: Gender Differences. Biomed J Sci \& Tech Res 19(4)2019. BJSTR. MS.ID.003334.

Keywords: Pulmonary artery hypertension; Gender differences; Heart dyniamics; Velocity of contraction; Velocity of relaxation; Rats

\begin{abstract}
Aim: The aim of this paper was to find out possible changes of heart work dynamics induced by pulmonary artery hypertension in male and female rats.

Materials and methods: Experiments were performed on the Wistar rats of both genders. Pulmonary hypertension (PAH) was induced by i.p. injection of monocrotaline $(60 \mathrm{mg} / \mathrm{kg} \mathrm{B.W.})$ on day 0 to 21 days observational period. After that, animal was sacrificed, hearts removed and papillary muscles from right ventricle isolated. Velocity of heart contraction $(+\mathrm{dF} / \mathrm{dt})$ and relaxation $(-\mathrm{dF} / \mathrm{dt})$ were measured. Additionally, pathomorphologic analysis of lung blood vessels has been carried out.

Result: PAH induced significant reduction of velocity of contraction $(+\mathrm{dF} / \mathrm{dt})$ and relaxation $(-\mathrm{dF} / \mathrm{dt})$ in both male $(+\mathrm{dF} / \mathrm{dt}: 3,41 \pm 0,33 \mathrm{mN} / \mathrm{s}$ vs. $2,53 \pm 0,31 \mathrm{mN} / \mathrm{s}, \mathrm{n}=6$, $\mathrm{p}<0,05 ;-\mathrm{dF} / \mathrm{dt}: 1,96 \mathrm{mN} / \mathrm{s} \pm 0,26$ vs. $1,2 \pm 0,17 \mathrm{mN} / \mathrm{s}, \mathrm{n}=6, \mathrm{p}<0,01)$ and female rats $(+\mathrm{dF} /$ dt: $3,09 \pm 0,35 \mathrm{mN} / \mathrm{s}$ vs. $1,86 \pm 0,22 \mathrm{mN} / \mathrm{s}, \mathrm{n}=6, \mathrm{p}<0,05 ;-\mathrm{dF} / \mathrm{dt}: 1,63 \pm 0,11 \mathrm{mN} / \mathrm{s}$ vs. 0,89 $\pm 0,097 \mathrm{mN} / \mathrm{s}, \mathrm{n}=6, \mathrm{p}<0,01)$.Adrenergic responsivness to noradrenaline with reference to both parameters of heart dynamics $(+\mathrm{dF} / \mathrm{dt}$ and $=\mathrm{dF} / \mathrm{dt})$ was increased significantly only in male rats. Additionally, PAH induced thickness of the lung blood vessels in both genders.
\end{abstract}

Conclusion: PAH reduced dynamic of heart work (especially relaxation velocity) in both male and female rats, but significantly increased sensitivity to adrenergic stimulation in male rats only.

\section{Introduction}

Pulmonary arterial hypertension (PAH) is defined as hemodynamic disease with mean arterial pressure, according to the last guidelines, more than $20 \mathrm{mmHg}[1,2]$, in pulmonary circulation, due to left ventricle heart disease, lung disease or thromboembolism [3,4]. Despite the tremendous improvement in therapy, PAH is still considered as serious clinical situation nedeed further research to better understanding and more efficous management $[5,6]$, especially related to heart contractility changes under such a condition. Moreover, a litlle is known about gender differences in pathophysiology and clinical manifestation as well as treatment of this disease. Therefore, we undertook this research in order to find out if PAH affects dyniamic of heart work in a gender dependent way using the rat model of pulmonary hypertension.

\section{Materials and Methods}

Experiments have been performed on Wistar rats of both genders, body weight 180-220g, kept under standard laboratory con dition (temperature of $23 \pm 2{ }^{\circ} \mathrm{C}$, a relative humidity of $53 \pm 2 \%$ and a fixed lighting cycle of 12 hours light /night, water ad libitum). The experimental protocol was approved by the Local Ethics Committee for Animal Experiments from Medical University of Gdansk, Poland. After a week's adaptation, the animals were divided into 4 groups: male control (MC), male with PAH (M-PAH), female control (FC) and female with PAH (F-PAH). M-PAH and F-PAH groups have been injected with monocrotaline (60 mg/kg B.W., i.p.), according to the well-established model of pulmonary hypertension in rats [7]. Groups MC and FC obtained the same volume of vehicle $(0,9 \%$ $\mathrm{NaCl}$ ). After 21 days, the rats were anesthetized by overdose with sodium pentobarbital ( $60 \mathrm{mg} / \mathrm{kg}$ ip). Then the chest was opened and the heart was quickly removed placed in a preparation dish with Krebs-Henseleit modified solution $(\mathrm{KH})$ and aerated with carbogen.

Then, as quickly as possible, a papillary muscle $>3 \mathrm{~mm}$ long and $<1 \mathrm{~mm}$ in diameter from the right ventricle was isolated [8]. The 
papillary muscle was placed in an organ bath of $2 \mathrm{ml}$ (Steiert organ bath, type 813 , DC temperature regulator, type 319, Hugo Sachs Elektronik, Germany). The isolated tissue was perfused with $\mathrm{KH}$ solution with the following composition: $\mathrm{NaCl} 120,4 ; \mathrm{KCl} 4,9 ; \mathrm{MgCl}_{2}$ x $6 \mathrm{H}_{2} \mathrm{O}$ 0,6; $\mathrm{CaCl}_{2}$ 2,5; $\mathrm{NaH}_{2} \mathrm{PO} 4$ x $\mathrm{H}_{2} \mathrm{O}$ 1,0; $\mathrm{NaHCO}_{3}$ 15,3; glucose 11,5 ; sodium pyruvate 2,0 . The rate of perfusion was approximately $8 \mathrm{ml} / \mathrm{min}$ and was maintained by means of a peristaltic pump (peristaltic pump, type 371, Unipan, Poland) and with a constant solution temperature of $37{ }^{\circ} \mathrm{C} \pm 0,5$. The solution was aerated with a gas mixture of $95 \% \mathrm{O}_{2}$ and $5 \% \mathrm{CO}_{2}$, so that the $\mathrm{pH}$ was kept constant at 7,4. To obtain the maximum contraction force, the tissue was maintained at $4 \mathrm{mN} \pm 0,12$ of resting force $(1 \mathrm{mN}=0,1 \mathrm{~g})$. Using two silver electrodes in contact with the papillary muscle, the tissue was stimulated with a $1 \mathrm{~Hz}$ square wave current, $3 \mathrm{~ms}$ pulse duration, $2000 \mathrm{~ms}$ base cycle length, $20 \%$ amplitude above the threshold voltage $(0,6 \mathrm{~V} \pm 0,3)$ generated by the unit insulating stimulator (ST-02, Experimentia, Hungary). Velocity of contraction and relaxation have been measured with an isometric transducer (F-30, HSE, Germany) and a differential with measuring bridge type 336 (HSE, Germany)

\section{Result}

The results were presented on two tables and one figure. (Table 1) contained mean values from 6 experiments related to the changes of velocity of contraction at basal condition and after stimulation by noradrenaline. PAH, either in male or female animals significantly decreased velocity of contraction and increased sensitivity to adrenergic stimulation in male rats. Similarly, velocity of relaxation was decreased in both male and females with $\mathrm{PAH}$, while increased sensitivity to adrenergic stimlulation related to this parameter (-dF/ dt) was observed only in male rats (Table 2).Pathomorphological analysis clearly shows that PAH induced thickness of the wall of blood pulmonary vessels (Figure 1).
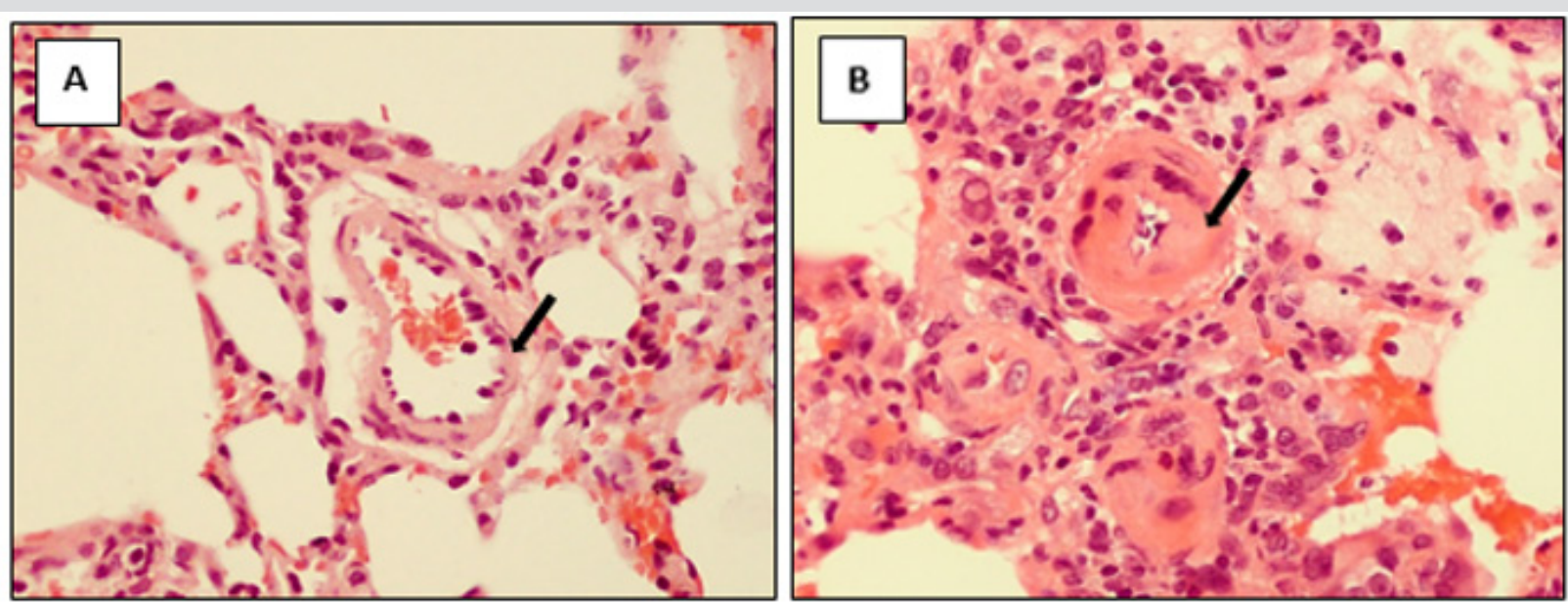

Male
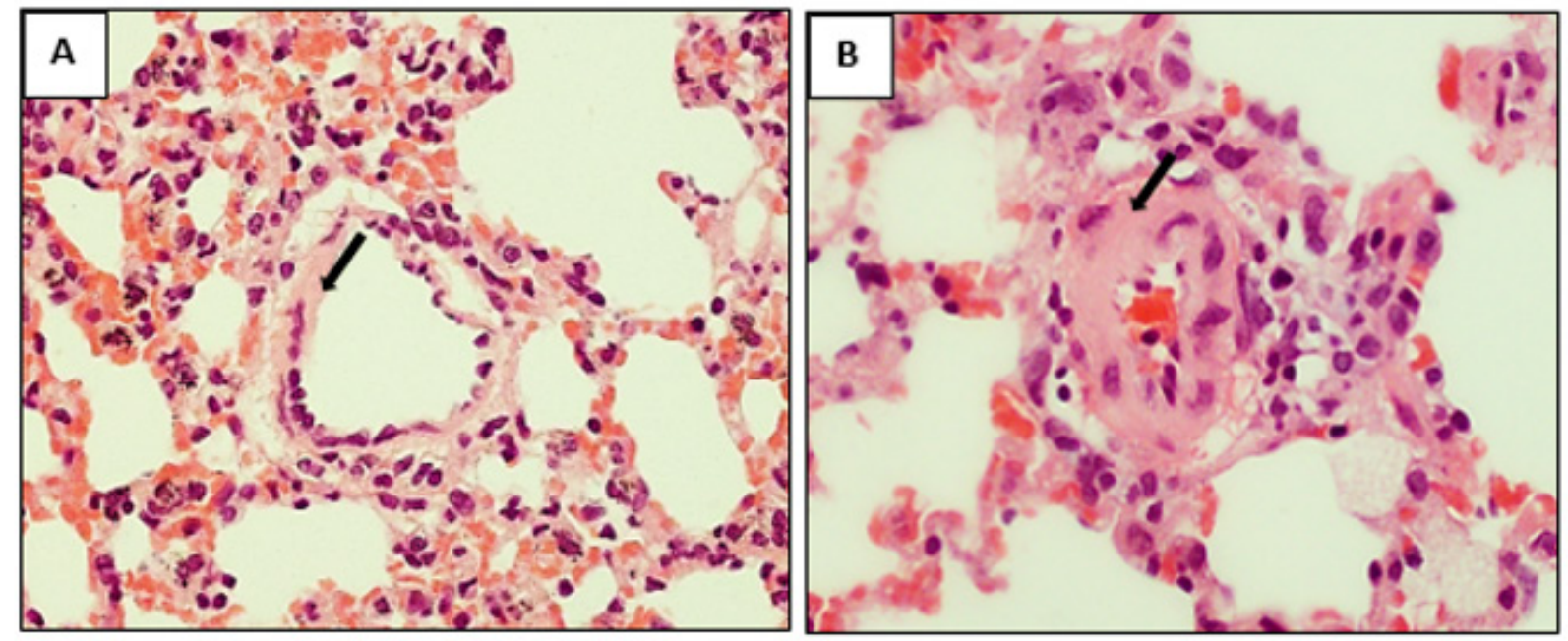

Female

Figure 1: Effect of monocrotaline-induced (MCT) changes in the thickness of the arterial wall (black arrows) inside the lungs of male and female rats. (A) Control group, (B) group with PAH (H \& E x 400). 
Table 1: The changes in the velocity of contraction $(+d F / d t)$ in rat papillary muscles induced by noradrenaline with MCTinduced pulmonary arterial hypertension.

\begin{tabular}{|c|c|c|}
\hline \multicolumn{3}{|c|}{ Parameter + dF / dt (mN/s) } \\
\hline \multicolumn{3}{|c|}{ Male } \\
\hline Groups & Control & $\mathrm{PAH}$ \\
\hline Control values & $3,41 \pm 0,33$ & $2,53 \pm 0,31^{*}$ \\
\hline \multicolumn{3}{|c|}{ Noradrenaline $(\mu \mathrm{M})$} \\
\hline 0,1 & $0,13 \pm 0,02$ & $0,27 \pm 0,09^{*}$ \\
\hline 0,3 & $0,22 \pm 0,05$ & $0,33 \pm 0,14^{*}$ \\
\hline 1 & $0,28 \pm 0,033$ & $0,27 \pm 0,11$ \\
\hline 3 & $0,28 \pm 0,025$ & $0,28 \pm 0,087$ \\
\hline 10 & $0,26 \pm 0,026$ & $0,28 \pm 0,093$ \\
\hline 30 & $0,23 \pm 0,039$ & $0,28 \pm 0,083$ \\
\hline 100 & $0,24 \pm 0,051$ & $0,19 \pm 0,068$ \\
\hline \multicolumn{3}{|c|}{ Female } \\
\hline Control values & $3,09 \pm 0,35$ & $1,86 \pm 0,22 a$ \\
\hline \multicolumn{3}{|c|}{ Noradrenaline $(\mu \mathrm{M})$} \\
\hline 0,1 & $0,23 \pm 0,06$ & $0,13 \pm 0,06$ \\
\hline 0,3 & $0,31 \pm 0,08$ & $0,18 \pm 0,07$ \\
\hline 1 & $0,36 \pm 0,089$ & $0,14 \pm 0,06$ \\
\hline 3 & $0,32 \pm 0,08$ & $0,2 \pm 0,047$ \\
\hline 10 & $0,41 \pm 0,1$ & $0,15 \pm 0,04$ \\
\hline 30 & $0,5 \pm 0,13$ & $0,14 \pm 0,06$ \\
\hline 100 & $0,46 \pm 0,14$ & $0,1 \pm 0,05$ \\
\hline
\end{tabular}

Each value represents the mean \pm S.E.M of $n=6$ experiment; ${ }^{*} \mathrm{p}<$ 0,05 vs. control; One-way ANOVA

Table 2: The changes in the velocity of relaxation $(-\mathrm{dF} / \mathrm{dt})$ in rat papillary muscles induced by noradrenaline with MCT-induced pulmonary arterial hypertension.

\begin{tabular}{|c|c|c|}
\hline \multicolumn{3}{|c|}{ Parametr - dF/dt(mN/s) } \\
\hline \multicolumn{3}{|c|}{ Male } \\
\hline Groups & Control & PAH \\
\hline Control values & $1,96 \pm 0,26$ & $1,2 \pm 0,17^{* *}$ \\
\hline \multicolumn{3}{|c|}{ Noradrenaline $(\boldsymbol{\mu M})$} \\
\hline 0,1 & $0,08 \pm 0,019$ & $0,15 \pm 0,055^{*}$ \\
\hline 0,3 & $0,09 \pm 0,011$ & $0,205 \pm 0,05 \mathrm{a}$ \\
\hline 1 & $0,1 \pm 0,024$ & $0,18 \pm 0,054$ \\
\hline 3 & $0,1 \pm 0,024$ & $0,18 \pm 0,07$ \\
\hline 10 & $0,14 \pm 0,036$ & $0,22 \pm 0,08$ \\
\hline 30 & $0,16 \pm 0,056$ & $0,165 \pm 0,081$ \\
\hline 100 & $0,19 \pm 0,064$ & $0,165 \pm 0,081$ \\
\hline \multicolumn{3}{|c|}{ Female } \\
\hline Control values & $1,63 \pm 0,11$ & $0,89 \pm 0,097 * *$ \\
\hline \multicolumn{3}{|c|}{ Noradrenaline $(\mu \mathrm{M})$} \\
\hline 0,1 & $0,065 \pm 0,023$ & $0,116 \pm 0,07$ \\
\hline 0,3 & $0,09 \pm 0,022$ & $0,101 \pm 0,075$ \\
\hline 1 & $0,08 \pm 0,019$ & $0,18 \pm 0,046$ \\
\hline 3 & $0,09 \pm 0,036$ & $0,15 \pm 0,059$ \\
\hline
\end{tabular}

\begin{tabular}{|c|c|c|}
\hline 10 & $0,09 \pm 0,022$ & $0,19 \pm 0,073$ \\
\hline 30 & $0,1 \pm 0,024$ & $0,22 \pm 0,078$ \\
\hline 100 & $0,14 \pm 0,044$ & $0,165 \pm 0,05$ \\
\hline
\end{tabular}

Each value represents the mean \pm S.E.M of $n=6$ experiments; ${ }^{*} \mathrm{p}<$ 0,$05 ;{ }^{* *} \mathrm{p}<0,01$ vs. control; One-way ANOVA

\section{Discussion}

$\mathrm{PAH}$ is a serious, incurable cardiovascular disease with high mortality rate. There are several signaling pathways involved in regulation of hemodynamic changes using for therapeutic intervention in this clinical situation: prostaglandin one, with prostacyclin as a modeling substance, endothelin receptors, nitric oxide and cGMP pathway (with PDE type V inhibitors to increase intracellular concentration of this second messenger) [9-11]. All mentioned strategies are aimed at vascular target, leading to relaxation of smooth muscle cells in lung blood vessels. However, a little is known about changes in heart work dynamics (velocity of contraction and relaxation of heart muscle) in PAH and possible intervention modulating heart contractility.

Our model of pulmonary hypertension (PAH) induced by monocrotaline with pathomorphological confirmation of vascular changes in lung blood vessels (Figure 1) clearly shows that hemodynamic changes appearing during development of pulmonary hypertension affect right heart dynamics in a different way in male and female rats. Namely, apart from significant reduction in velocity of contraction and relaxation in both genders, PAH enhanced sensitivity to adrenergic stimulation related to both parameters determining a dynamic of heart work, only in males. Our previous work on the rat tail artery model demonstrated that PAH increased sensitivity of vascular adrenergic receptors to phenilephrine [12], which was attenuated in the presence of estrogen. Moreover, we have shown that sinoatrial cells regulating heart rate were more sensitive to isoprenaline in female rats with PAH [13]. One of the reason for this reaction could be related to attenuated activity of ATP-sensitive $\mathrm{K}+$ channels in females under such a condition [13]. Taken together these data suggest that PAH realated increase sensitivity to adrenergic stimulation is attenuated by estrogen in heart muscle and smooth muscle of the blood vessels, but not in sinoatrial pacmaker cells. This data could be of clinical interest in preparation of the new therapeutic strategy for treatment of PAH in a gender-dependent way.

To conclude, pulmonary arterial hypertension affects significantly heart work dynamics (especially heart relaxation) and enhances sensitivity to adrenergic stimulation in male rats. This data could be helpful in clinical management of PAH.

\section{Acknowledgement}

Tha authors are grateful to prof. Z. Jankowski from Department of Forensic Medicine, Medical University of Gdansk, Poland, for help in pathomrphological research 


\section{References}

1. Galie N, Channick RN, Frantz RP, Torbicki A, Simonneau G, et al. (2016) 2015ESC/ERS guidelines for the diagnosis and treatment of pulmonary hypertension. The Joint Task Force for the Diagnosis and Treatment of Pulmonary Hypertensionof the European Society of Cardiology (ESC) and the European respiratory Society (ERS) endorsed by Association for European Pediatric and Congenital Cardiology (AEPC), International Society for Heart and Lung Transplantation (ISHLT). Eur H J 37 (1): $67-$ 119.

2. Simonneau G, Montani D, Celermajer DS, Denton CP, Gatzoulis MA, et al. (2019) Haemodinamic definitions and updated clinical classification of pulmonary hypertension. Eur Respir J 53 (1).

3. Sitbon O, Gomberg-Maitland M, Granton J, Michael I. Lewis, Stephen C. Mathai, et al. (2019) Clinical trial design and new therapies for pulmonary arterial hypertension. Eur Respir J 53 (1).

4. Hoeper MM, Apitz C, Grünig E, Kaemmerer H, Kabitz HJ, et al. (2018) Targeted therapy of pulmonary arterial hypertension: Updated recommendations from the Cologne Consensus Conference 2018. Int J Cardiol 272S: 37-45

5. Hoeper MM, Benza RL, Corris P, De Perrot M, Fadel E, et al. (2019) Intensive care, right ventricular support and lung transplantation in patients with pulmonaryhypertension. Eur Respir J 53(1)

6. Sisniega C, Zayas N, Pulido T (2019) Advances in medical therapy for pulmonary arterial hypertension. Curr Opin Cardiol. 2019; 34(1): 98103.

\section{ISSN: 2574-1241}

DOI: 10.26717/BJSTR.2019.19.003334

Ivan Kocic. Biomed J Sci \& Tech Res

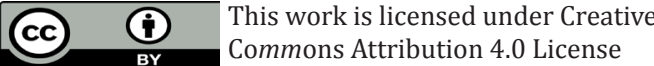

Submission Link: https://biomedres.us/submit-manuscript.php
7. Naeije R, Dewachter L (2007) Animal models of pulmonary arterial hypertension. Rev Mal Respir 24(4 Pt 1): 481-496.

8. Kocić I, Konstański Z (1998) The effects of potassium channel modulators on the simulated ischaemia-induced changes in contractility and responsiveness to phenylephrine of rat-isolated papillary muscle. Pharmacol Res 38(3): 183-189.

9. Harari S, Elia D, Humbert M (2018) Pulmonary hypertension in parenchymal lung diseases: any future for new therapies? Chest 153(1): 217-223.

10. Bredmose PP, Buskop C, Lømo AB (2019) Inhaled nitric oxide might be a contributing tool for successful resuscitation of cardiac arrest related to pulmonary hypertension. Scand J Trauma Resusc Emerg Med 27(1): 22.

11. Zelt JGE, Chaudhary KR, Cadete VJ (2019) Medical therapy for heart failure associated with pulmonary hypertension. Circ Res 124(11): 1551-1567.

12. Kocić I, Szczepańska R, Wapniarska I (2010) Estrogen-induced relaxation of the rat tail artery is attenuated in rats with pulmonary hypertension. Pharmacol Rep 62(1): 95-99.

13. Kocic I, Sztormowska K (2009) Pulmonary hypertension modifies responsiveness of sinoatrial cells of rat hearts to adrenomimetics and activators of ATP-sensitive $\mathrm{K}+$ channels in a gender-dependent way. J Physiol Pharmacol 60(1): 165-169.

$\begin{array}{ll}\text { BIOMEDICAL } & \text { Assets of Publishing with us } \\ \text { RESEARCHES } & \text { - Global archiving of articles } \\ & \text { - Immediate, unrestricted online access } \\ & \text { - Rigorous Peer Review Process } \\ \end{array}$

